\section{JURNAL ABDIMAS

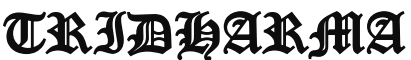

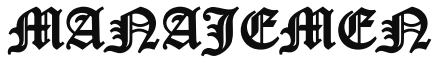

P-ISSN 2715-7105, E-ISSN 2716-070X

Jurnal ABDIMAS Vol. 1,No.2, Mei 2020, Hal (67-74)

@Prodi Manajemen Fakultas Ekonomi Universitas Pamulang

Email: abdimasjurnal.unpam@gmail.com Telp: (021) 741-2566

\title{
RENDAHNYA INTENSI ANAK UNTUK CURHAT KEPADA ORANG TUA PADA SISWA MTS MATHLAUL ANWAR
}

\author{
Sugeng Widodo ,Lilis Suryani, Lili Sularmi, Yuga Pratama, Rini Dianti \\ Dosen Ekonomi Fakultas Ekonomi Universitas Pamulang \\ Email dosen01632@unpam.ac.id, dosen00437@unpam.ac.id, dosen02112@unpam.ac.id \\ , dosen01425@unpam.ac.id
}

\begin{abstract}
ABSTRAK
Curhat atau curahan hati merupakan saat di mana satu orang mencoba untuk menceritakan sesuatu kepada orang-orang yang dianggap dekat, dan biasanya yang diceritakan itu masalah personal.Misal tentang pekerjaan, pasangan, keluarga, dan lain sebagainya. Mungkin orang akan berasumsi bahwa orang yang curhat itu butuh pendapat orang lain guna mencari solusi untuk masalahnya. Tapi ada juga yang curhat bukan untuk mencari solusi, melainkan hanya ingin didengar kisahnya.Karena wanita kebanyakan menceritakan masalah itu lebih karena ingin empati dan simpati.Jadi ketika diberikan solusi yang simple dan to the point, justru merasa tidak didengarkan.Kadang ada juga pria yang seperti itu.Secara garis besar orang curhat ada 3, pertama ingin mencari solusi, kedua ingin pengakuan atau respons positif, ketiga ingin mencari perhatian. Curhat bukan cuma karena ingin mencari solusi, tapi bisa juga karena alasan lain.Curhat (curahan hati) dibutuhkan setiap orang karena tak selamanya manusia bisa mengatasi kegundahan, mengadukan kegelisahan, menguraikan rasa sakit hati dan menyelesaikan permasalahannya sendiri.Curhat bisa juga ditindaklanjuti sebagai aktivitas berbagi pengalaman, bertukar pikiran dan berbagi perasaan, terutama dengan orang-orang terdekat yang kita percayai.Karena itu, curhat menjadi kebutuhan psikis yang dianggap penting oleh banyak orang.Sebagai ajang berbagi, curhat memiliki banyak manfaat, asal dicurahkan kepada orang yang tepat.Pertama, melegakan dan menenangkan perasaan.Di saat sedih dan gundah, kita butuh teman walaupun hanya untuk sekedar mendengarkan keluh kesah kita.Curhat kepada sahabat, keluarga dan orang-orang terdekat paling tidak bisa meringankan beban yang menghimpit perasaan.Apalagi jika orang tempat kita curhat memberikan respon yang baik.Hati dan pikiran kita bisa jauh lebih tenang.Kedua, curhat bisa membuat hubungan semakin dekat dan erat, baik dengan keluarga maupun sahabat.Kedekatan timbul karena rasa nyaman, rasa percaya dan adanya rasa menghargai dan dihargai. Orang yang jadi tempat curhat akan merasa dihargai dan dipercaya karena umumnya curhat menyangkut masalah pribadi, sehingga ia juga bisa lebih memahami pribadi sahabatnya yang curhat tersebut. Demikian pula orang yang curhat, dengan adanya respon dari pendengar curhatnya, ia merasa dihargai, dimengerti dan merasa orang tersebut
\end{abstract}

\section{Kata Kunci:Intensi curhat, Anak, Orang Tua}

\section{ABSTRAC}

Confide is a time when one person tries to tell something to people who are considered close, and usually what is told is a personal matter. For example about work, spouse, family, and so forth. Maybe people will assume that the person who is in need of opinions of others in order to find solutions to the problem. But there are also those who 


\section{JURNAL ABDIMAS

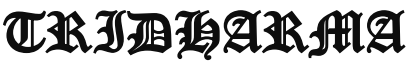 \\ AtA}

P-ISSN 2715-7105, E-ISSN 2716-070X

Jurnal ABDIMAS Vol. 1,No.2, Mei 2020, Hal (67-74)

@ Prodi Manajemen Fakultas Ekonomi Universitas Pamulang

Email: abdimasjurnal.unpam@gmail.com Telp: (021) 741-2566

vent not to find a solution, but only want to be heard. Because women mostly talk about the problem more because they want empathy and sympathy. So when given a solution that is simple and to the point, just feel not heard. Sometimes there are men like that. Broadly speaking there are 3 people confide in, firstly want to find a solution, secondly want recognition or positive response, thirdly want to seek attention. Confide not only because you want to find a solution, but also for other reasons. Confide (pouring heart) is needed by everyone because not always humans can overcome anxiety, complain anxiety, describe pain and resolve their own problems. Confidence can also be followed up as an activity to share experiences, exchange ideas and share feelings, especially with those closest to us that we trust. Therefore, vent to be a psychological need that is considered important by many people. As a place to share, vent has many benefits, as long as it is devoted to the right person. First, relief and calm feelings. When times are sad and depressed, we need friends even if just to listen to our complaints. Confide in best friends, family and those closest to you can at least ease the burden of your feelings. Especially if the people we confide in give a good response. Our hearts and minds can be much calmer. Second, confide can make the relationship closer and closer, both with family and friends. Closeness arises because of a sense of comfort, a sense of trust and a sense of respect and appreciation. People who become a vent will feel valued and trusted because it is generally related to personal matters, so that he can also better understand the personal friend of the confide. Likewise, the person who is confide in, with the response from the audience, he feels valued, understood and feels of that person

\section{Keywords: Intentions vent, Children, Parents}

\section{PENDAHULUAN}

Curhat atau curahan hati merupakan saat di mana satu orang mencoba untuk menceritakan sesuatu kepada orang-orang yang dianggap dekat, dan biasanya yang diceritakan itu masalah personal.Misal tentang pekerjaan, pasangan, keluarga, dan lain sebagainya. Mungkin orang akan berasumsi bahwa orang yang curhat itu butuh pendapat orang lain guna mencari solusi untuk masalahnya. Tapi ada juga yang curhat bukan untuk mencari solusi, melainkan hanya ingin didengar kisahnya.Karena wanita kebanyakan menceritakan masalah itu lebih karena ingin empati dan simpati.Jadi ketika diberikan solusi yang simple dan to the point, justru merasa tidak didengarkan.Kadang ada juga pria yang seperti itu.

Secara garis besar orang curhat ada 3 , pertama ingin mencari solusi, kedua ingin pengakuan atau respons positif, ketiga ingin mencari perhatian. Curhat bukan cuma karena ingin mencari solusi, tapi bisa juga karena alasan lain.
Curhat (curahan hati) dibutuhkan setiap orang karena tak selamanya manusia bisa mengatasi kegundahan, mengadukan kegelisahan, menguraikan rasa sakit hati dan menyelesaikan permasalahannya sendiri.Curhat bisa juga ditindaklanjuti sebagai aktivitas berbagi pengalaman, bertukar pikiran dan berbagi perasaan, terutama dengan orang-orang terdekat yang kita percayai.Karena itu, curhat menjadi kebutuhan psikis yang dianggap penting oleh banyak orang.Sebagai ajang berbagi, curhat memiliki banyak manfaat, asal dicurahkan kepada orang yang tepat.Pertama, melegakan dan menenangkan perasaan.Di saat sedih dan gundah, kita butuh teman walaupun hanya untuk sekedar mendengarkan keluh kesah kita.Curhat kepada sahabat, keluarga dan orang-orang terdekat paling tidak bisa meringankan beban yang menghimpit perasaan.Apalagi jika orang tempat kita curhat memberikan respon yang baik. Hati dan pikiran kita bisa jauh lebih tenang.Kedua, curhat bisa membuat 


\section{JURNAL ABDIMAS

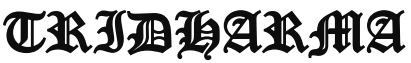 \\ ALA:}

P-ISSN 2715-7105, E-ISSN 2716-070X

Jurnal ABDIMAS Vol. 1,No.2, Mei 2020, Hal (67-74)

@ Prodi Manajemen Fakultas Ekonomi Universitas Pamulang

Email: abdimasjurnal.unpam@ gmail.com Telp: (021) 741-2566 hubungan semakin dekat dan erat, baik dengan keluarga maupun sahabat.Kedekatan timbul karena rasa nyaman, rasa percaya dan adanya rasa menghargai dan dihargai. Orang yang jadi tempat curhat akan merasa dihargai dan dipercaya karena umumnya curhat menyangkut masalah pribadi, sehingga ia juga bisa lebih memahami pribadi sahabatnya yang curhat tersebut. Demikian pula orang yang curhat, dengan adanya respon dari pendengar curhatnya, ia merasa dihargai, dimengerti dan merasa orang tersebut bisa dipercaya. Saling percaya, saling memahami dan pengertian merupakan factor yang bisa mempererat dan melanggengkan hubungan antar manusia. Di sisi lain, kita bisa jadikan curhat sebagai alat komunikasi yang bisa mempererat hubungan dengan Yang Maha Sempurna. Mengadu dan memohon petunjuk melalui doa, selain bisa menenangkan juga bisa meningkatkan kehusyukan dalam beribadah. Ketiga, curhat bisa membuat kita mendapatkan pencerahan dan solusi yang baik, terutama jika kita curhat kepada orang yang betulbetul tepat dari segi profesi, dan kualitas dan kredibilitasnya.Misalnya, para ahli yang dianggap mampu menangani permasalahan yang dihadapi.Secara teoritis, para ahli memiliki kemampuan ilmiah dan logis dalam memahami permasalahan kita.Mereka juga umumnya lebih berpengalaman menangani permasalahan yang beragam, sehingga bisa membantu memberikan gambaran solusi dan memberikan pencerahan terhadap hati dan pikiran kita.Dokter, psikolog, counselor dan para ulama merupakan contoh para pakar yang professional dan memiliki kode etik yang dipertanggungjawabkan terhadap Tuhan dan makhluk-Nya.Idealnya, aman jadi tempat curhat karena bisa menjamin kerahasiaan.Dalam beberapa tahun terakhir, kegiatan curhat bahkan dikemas dan dimodifikasi menjadi bentuk yang lebih variatif.Misalnya, menjadi media dakwah yang bisa ditonton dan memberikan tuntunan juga.Curhat interaktif melalui media dan teknologi yang komunikatif mengenai permasalahan sehari-hari yang berkaitan dengan pandangan dan hukum agama, sejatinya bisa menjadi pencerahan dan wawasan keilmuan yang memperkaya batin kita.Namun, perlu diingat bahwa sesuatu yang menyangkut makhluk selalu memiliki 2 sisi, manfaat dan mudharat.Mudharat curhat sebetulnya lebih kepada pilihan kita sendiri, baik waktu, tempat maupun orang yang kita jadikan tempat curhat.Curhat kepada orang yang tidak tepat bisa menambah masalah baru.Bisa saja rahasia atau aib kita menjadi tersebar karena yang dijadikan tempat curhat tidak amanah.Mungkin juga kita terlalu banyak "mengumbar" curhat kepada banyak orang, sehingga tidak mendapatkan solusi yang semestinya.Biasanya, semakin banyak orang tahu dan terlibat dalam suatu masalah, terutama masalah pribadi, masalah malah melebar dan sulit diselesaikan.Keterlibatan banyak orang yang tidak benar-benar memahami inti masalah umumnya memang bisa memperkeruh suasana yang akhirnya kita juga yang kebingungan dan terbebani.Jangan salah pilih sahabat untuk curhat dan jangan jadikan tempat curhat kita sebagai "pembuangan" semata. Kalau masalahnya sudah bisa dipecahkan, seolaholah tidak dibutuhkan lagi, sehingga ia merasa dibuang dan tidak dihargai. Perlu kita ingat bahwa curhat tidak sekedar berkeluh kesah, tetapi juga berbagi pengalaman dan bertukar pikiran. Saling, itu berarti ada timbal balik antara keduanya kan? Ya, kita upayakan kita juga bisa menjadi tempat curhat yang baik bagi orang lain, supaya manfaatnya betul-betul dirasakan bersama.Curhat itu penting, tetapi pilih orang yang tepat untuk dijadikan tempat curhat.Tepat secara profesi, sifat dan kepribadiannya, serta tepat waktu dan tempatnya.Pada akhirnya, semua kembali kepada diri kita sendiri.Curhat hanya sebuah media untuk mengkomunikasikan permasalahan dan 


\section{JURNAL ABDIMAS

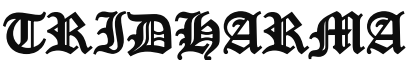

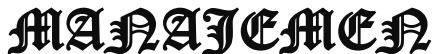

P-ISSN 2715-7105, E-ISSN 2716-070X

Jurnal ABDIMAS Vol. 1,No.2, Mei 2020, Hal (67-74)

@ Prodi Manajemen Fakultas Ekonomi Universitas Pamulang

Email: abdimasjurnal.unpam@gmail.com Telp: (021) 741-2566 tempat berbagi untuk mendapatkan pencerahan atau solusi yang baik.Dalam beberapa tahun terakhir, kegiatan curhat bahkan dikemas dan dimodifikasi menjadi bentuk yang lebih variatif. Misalnya, menjadi media dakwah yang bisa ditonton dan memberikan tuntunan juga. Curhat interaktif melalui media dan teknologi yang komunikatif mengenai permasalahan sehari-hari yang berkaitan dengan pandangan dan hokum agama, sejatinya bisa menjadi pencerahan dan wawasan keilmuan yang memperkayabatinkita.Namun, perlu diingat bahwa sesuatu yang menyangkut makhluk selalu memiliki 2 sisi, manfaat dan mudharat. Mudharat curhat sebetulnya lebih kepada pilihan kita sendiri, baik waktu, tempat maupun orang yang kita jadikan tempat curhat. Curhat kepada orang yang tidak tepat bisa menambah masalah baru. Bisa saja rahasia atau aib kita menjadi tersebar karena yang dijadikan tempat curhat tidak amanah. Mungkin juga kita terlalu banyak "mengumbar" curhat kepada banyak orang, sehingga tidak mendapatkan solusi yang semestinya. Biasanya, semakin banyak orang tahu dan terlibat dalam suatu masalah, terutama masalah pribadi, masalah malah melebar dan sulit diselesaikan. Keterlibatan banyak orang yang tidak benar-benar memahami inti masalah umumnya memang bisa memperkeruh suasana yang akhirnya kita juga yang kebingungan danterbebani.Jangan salah pilih sahabat untuk curhat dan jangan jadikan tempat curhat kita sebagai "pembuangan" semata. Kalau masalahnya sudah bisa dipecahkan, seolah-olah tidak dibutuhkan lagi, sehingga ia merasa dibuang dan tidak dihargai. Perlu kita ingat bahwa curhat tidak sekedar berkeluh kesah, tetapi juga berbagi pengalaman dan bertukar pikiran. Saling, itu berarti ada timbal balik antara keduanya kan? Ya, kita upayakan kita juga bisa menjadi tempat curhat yang baik bagi orang lain, supayamanfaatnyabetulbetuldirasakan.

\section{RUMUSAN MASALAH}

Persoalan yang dihadapi oleh Guru dan orang tua dalam menyampaikan sulitnya curat anak sehingga adalah sebagai berikut ini:

1. Bagaimana dampak anak yang tidak ada curhat kepada orang tua pada siswa MTS Matlaul Anwar Pamulang?

2. Bagaimana upaya orang tua agar anak dapat curhat kepada orang tua pada siswa MTS Matlaul Anwar Pamulang?

\section{TUJUAN PELAKSANAAN}

Tujuan umum dari kegiatan pengabdian kepada masyarakat ini adalah:

1. Memberikan informasi terkait dampak positif jika anak dapat curhat kepada Orang tua pada siswa MTS Matlaul Anwar Pamulang.

2. Memberikan informasi tentang upaya pentingnya curhat anak kepada Orang tua di kalangan siswa MTS Matlaul Anwar Pamulang.

\section{TINJAUAN PUSTAKA \\ 1. Pengertian Motivasi}

Curhat atau curahan hati merupakan saat di mana satu orang mencoba untuk menceritakan sesuatu kepada orang-orang yang dianggap dekat, dan biasanya yang diceritakan itu masalah personal.Misal tentang pekerjaan, pasangan, keluarga, dan lain sebagainya. Mungkin orang akan berasumsi bahwa orang yang curhat itu butuh pendapat orang lain guna mencari solusi untuk masalahnya. Tapi ada juga yang curhat bukan untuk mencari solusi, melainkan hanya ingin didengar kisahnya.Karena wanita kebanyakan menceritakan masalah itu lebih karena ingin empati dan simpati.Jadi ketika diberikan solusi yang simple dan to the point, justru merasa tidak didengarkan.Kadang ada juga pria yang seperti itu.

Secara garis besar orang curhat ada 3 , pertama ingin mencari solusi, kedua ingin 


\section{JURNAL ABDIMAS

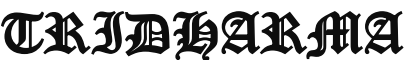

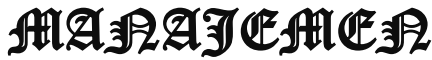

P-ISSN 2715-7105, E-ISSN 2716-070X

Jurnal ABDIMAS Vol. 1,No.2, Mei 2020, Hal (67-74)

@Prodi Manajemen Fakultas Ekonomi Universitas Pamulang

Email: abdimasjurnal.unpam@gmail.com Telp: (021) 741-2566 pengakuan atau respons positif, ketiga ingin mencari perhatian. Curhat bukan cuma karena ingin mencari solusi, tapi bisa juga karena alasan lain.

1.1 Dampak Positif Curhat.

1. Orang tua akan tahu kondisi anak.

2. Orang tua akan memahami perasaan anak.

3. Anak akan lebih terkontrol dan terarah.

1.2 Dampak Negatif jika tidak curhat.

1. Orang tua tidak akantahu kondisi anak.

2. Orang tua tidak akan memahami perasaan anak.

3. Anak akan tidak terkontrol dan terarah.

\section{METODE PELAKSANAAN}

Untuk bisa lebih memahami konteks yang saya maksud, mari kita bisa samasama melihat kondisi anak-anak kita. Agar semakin baik dengan kita terus melakukan berupaya semoga menjadi lebih baik. Melalui pendekatan Pendampingan, penyuluhan dan praktek.

Metode pendekatan yang digunakan dalam kegiatan ini adalah :

\subsection{Realisasi Pemecahan Masalah}

Berdasarkan permasalahan utama mitra yang telah dijelaskan pada poin sebelumnya, maka solusi permasalahan yang di tawarkan kepada mitra adalah:

Solusi untuk mengembalikan respect siswa terhadap guru ;

Bagaimana cara mengembalikan respect siswa terhadap guru?" Merupakan pertanyaan yang tepat daripada "Bagaimana cara mengatasi menurunnya respect siswa terhadap guru?'.Karena masalah ini telah menjadi masalah umum didunia pendidikan masa sekarang.

Guru harus mempunyai strategi atau cara untuk mendapatkan rasa hormat (respect) siswa, agar proses belajar mengajar berjalan dengan baik. Sebagaimana telah ditulis oleh Edna
Sackson seorang guru yang berasal dari Australia (whatedsaid.wordpress.com: 2010), ada 10 cara untuk mendapatkan respect (rasa hormat) siswa yaitu ;

1. Hormati siswa anda, untuk mendapatkan rasa hormat dari siswa, guru harus menghormati siswa terlebih dahulu. Hormatilah sikap dan sifat positif siswa, pendapat siswa, karya siswa dan secara automatis maka mereka akan menghormati guru tersebut.

2. Buatlah perjanjian dengan siswa, ini bertujuan untuk membuat peraturan kelas yang akan disetujui oleh siswa sesuai batas kemampuan siswa dan dikombinasikan dengan aturan sekolah. Sehingga siswa akan lebih patuh pada peraturan yang telah mereka buat sendiri.

3. Jadilah bagian dari mereka, guru harus lebih jeli dimana harus menempatkan diri dalam situasi belajar. Dimana guru bisa jadi teman belajar, fasilitator, dan guru bukan menjadi diktator dalam kelas.

4. Memberikan hak kebutuhan fisik mereka, misalnya untuk buang air ditengah proses belajar atau makan dan minum pada waktu yang telah diberikan.

5. Bersikap adil dan wajar, sebagai guru harus dituntut adil sehingga tidak pilih kasih atau berpihak pada seseorang atau satu kelompok. Dan bersikap wajar, bukan membuat suasana yang tidak mungkin sehingga membaluat ketegangan antar siswa.

6. Humoris, sikap yang menyenangkan dari guru akan membuat pelajaran menjadi rileks dan jauh dari ketegangan. Dan tegaslah apabila terjadi lelucon siswa yang merugikan siswa lain.

7. Berikan ruang berekspresi siswa, berikan siswa motivasi agar berfikir kreatif dan inovatif dalam 


\section{JURNAL ABDIMAS

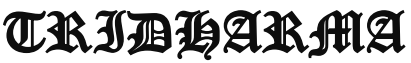

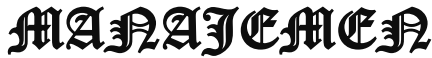

P-ISSN 2715-7105, E-ISSN 2716-070X

Jurnal ABDIMAS Vol. 1,No.2, Mei 2020, Hal (67-74)

@Prodi Manajemen Fakultas Ekonomi Universitas Pamulang

Email: abdimasjurnal.unpam@ gmail.com Telp: (021) 741-2566 menentukan pembelajaran. Dan jangan membatasi mereka dengan cara - cara kaku atau guru yang bersifat text book.

8. Jujur, jangan ada pura - pura. Katakan salah bila salah dan benar bila benar dengan tutur kata yang baik agar tidak menyakiti hati dan diterima oleh siswa.

9. Guru adalah manusia, katakan maaf kalau guru melakukan kesalahan dan jangan melemparkan kesalahan kepada siswa.

10. Kebebasan, berikan siswa kebebasan untuk berpendapat dan memilih dalam pembelajaran. Jangan selalu memvonis semua pendapat dan pilihan siswa salah. Biarkan dulu mereka berpendapat dan memilih sampai ada pendapat atau pilihan yang benar. Dan kalaupun belum ada maka ini adalah tugas guru untuk membenarkan dan menjelaskan pendapat dan pilihan yang benar.

11. Membangun kesadaran siswa untuk mengetahui bagaimana pentingnya memiliki intensi tinggi untuk curhat kepada kedua orang tuanya.

\section{HASIL DAN PEMBAHASAN}

\section{Pendampingan}

Pada kegiatan ini dilakukan dengan cara membuka mindset tentang pentingnya memiliki intensi tinggi untuk curhat pada kedua orang tuanya.Bermain merupakan sebuah kegiatan yang sangat disukai anakanak.Bagaimana tidak, dengan bermain anak dapat bebas melakukan kegiatan yang disukainya dan mendapatkan hiburan.Sebagian besar anak-anak menghabiskan waktunya dengan bermain, dapat dikatakan bahwa bermain merupakan salah satu kegiatan utama bagi anakanak.Banyak orang beranggapan bahwa bermain hanya membuang-buang waktu bagi anak-anak.Ini menjadikan banyak orang tua melarang anaknya untuk bermain dan lebih membuat sibuk anak dengan kegiatan-kegiatan yang serius seperti les tambahan pelajaran dan sejenisnya.Memang tidaklah salah, namun dengan bimbingan yang tepat, kegiatan bermain dapat diselaraskan dan digabungkan dengan belajar sehingga bermain selain anak-anak menjadi senang juga mendapatkan ilmu dari belajar.

Yang perlu ditekankan adalah pendampingan dari orang tua, guru, ataupun orang yang terdekat dengan anak agar terus membimbing dan mengawasi ketika anak bermain.Kegiatan bermain ini hendaknya dilakukan dengan perencanaan sehingga bermain dan belajar dapat berjalan dengan bersamaan serta efektif.

2. Penyuluhan

Aspek yang akan dikaji dalam kegiatan ini adalah factor tentang pentingnya memiliki intensi tinggi untuk curhat pada kedua orang tuanya.Konseli sebagai seorang individu yang sedang berada dalam proses berkembang atau menjadi (on becoming), yaitu berkembang ke arah kematangan atau kemandirian. Untuk mencapai kematangan tersebut, konseli memerlukan bimbingan karena mereka masih kurang memiliki pemahaman atau wawasan tentang dirinya dan lingkungannya, juga pengalaman dalam menentukan arah kehidupannya. Disamping itu terdapat suatu keniscayaan bahwa proses perkembangan konseli tidak selalu berlangsung secara mulus, atau bebas dari masalah. Dengan kata lain, proses perkembangan itu tidak selalu berjalan dalam alur linier, lurus, atau searah dengan potensi, harapan dan nilainilai yang dianutPerkembangan konseli tidak lepas dari pengaruh lingkungan, baik fisik, psikis maupun sosial. Sifat yang melekat pada lingkungan adalah perubahan. Perubahan yang terjadi dalam lingkungan dapat mempengaruhi gaya hidup (life style) warga masyarakat Apabila perubahan yang terjadi itu sulit diprediksi, atau di luar jangkauan kemampuan, maka akan melahirkan kesenjangan perkembangan perilaku konseli, seperti terjadinya stagnasi (kemandegan) perkembangan, masalah- 


\section{JURNAL ABDIMAS

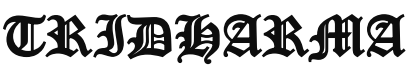

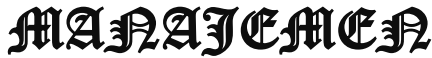

P-ISSN 2715-7105, E-ISSN 2716-070X

Jurnal ABDIMAS Vol. 1,No.2, Mei 2020, Hal (67-74)

@Prodi Manajemen Fakultas Ekonomi Universitas Pamulang

Email: abdimasjurnal.unpam@gmail.com Telp: (021) 741-2566 masalah pribadi atau penyimpangan perilaku. Perubahan lingkungan yang diduga mempengaruhi gaya hidup, dan kesenjangan perkembangan tersebut, di antaranya: pertumbuhan jumlah penduduk yang cepat, pertumbuhan kota-kota, kesenjangan tingkat sosial ekonomi masyarakat, revolusi teknologi informasi, pergeseran fungsi atau struktur keluarga, dan perubahan struktur masyarakat dari agraris ke industri.

\section{Praktek}

Pada kegiatan ini akan diajarkan bagaimana cara agar pentingnya memiliki intensi tinggi untuk curhat belajar pada kedua orang tuanya. Kerja sama guru dan orang tua siswa sangat menentukan keberhasilan siswa. Melalui kerja sama ini guru dan orang tua siswa saling bantu membantu serta saling pengertian antara guru dan orang tua siswa demi keuntungan anak didik, dimana masing-masing membawa pengaruh demikian inilah maka terwujudlah saling mengerti dan bantumembantu antara keduanya untuk meningkatkan prestasi belajar siswa. Saling bantu membantu saling pengertian antara guru dengan orang tua siswa sangat diperlukan. Bahwa guru dan orang tua siswa kerja samanya sangat bermanfaat dalam meningkatkan prestasi belajar siswa. Untuk menciptakan hal tersebut, guru-guru dan orang tua harus berusaha menempuh langkah- langkah apa yang harus dilakukan sehingga kerja sama dapat terjalin dengan baik antara kedua bela pihak baik yang berhubungan orang tua siswa maupun guru dengan lingkungan masyarakat. Maka dari itu kerja sama orang tua siswa dan guru yaitu :

a. Mengadakan pertemuan pada hari penerimaan siswa baru.

Mengadakan surat menyurat antara sekolah dan keluarga

c. Adanya daftar nilai rapor

d. Kunjungan guru ke rumah orang tua siswa atau sebaliknya.

e. Mengadakan perayaan, pesta sekolah atau pameran-pameran hasil kerja siswa. f. Yang terpenting ialah mendirikan perkumpulan orang tua dan guru.

\section{KESIMPULAN DAN SARAN \\ Kesimpulan}

Hasil kegiatan ini dapat memberikan manfaat bagi siswa di MTs Matlaul Anwar Pamulang tentang pentingnya curhat anak kepada guru dan orang tua, agar segala permasalahan dan ketidak tahuan anak-anak akan mendapt jawaban dari ilmu dan pengalaman para guru dan orang tua. Maka perlu adanya pendekatan yang baik dengan cara-cara pentuluhan dan diskusi yang nyaman.

\section{DAFTAR PUSTAKA}

http://whatedsaid.wordpress.com/2010/08/ 28/10-ways-to-get-your-students-respect/ http://akhmadsudrajat.wordpress.com/2012 /10/28/hubungan-guru-dengan-siswa/ http://dunia.news.viva.co.id/news/read/281 864-indonesia-di-mata-pengajar-australia http://edukasi.kompasiana.com/2010/01/19 /ketika-rasa-hormat-dan-tanggung-jawabitu-dipertanyakan/

http://edukasi.kompasiana.com/2012/08/21 /siswa-tuh-suka-kalau-gurunya$\underline{487042 . h t m l}$

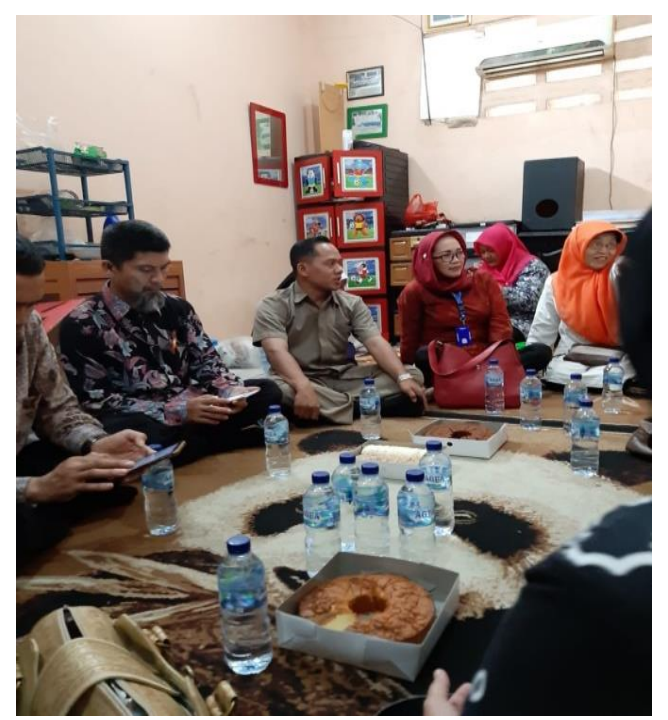




\section{JURNAL ABDIMAS

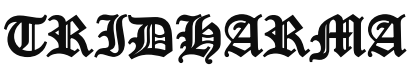 丹IA}

P-ISSN 2715-7105, E-ISSN 2716-070X

Jurnal ABDIMAS Vol. 1,No.2, Mei 2020, Hal (67-74)

@ Prodi Manajemen Fakultas Ekonomi Universitas Pamulang

Email: abdimasjurnal.unpam@gmail.com Telp: (021) 741-2566
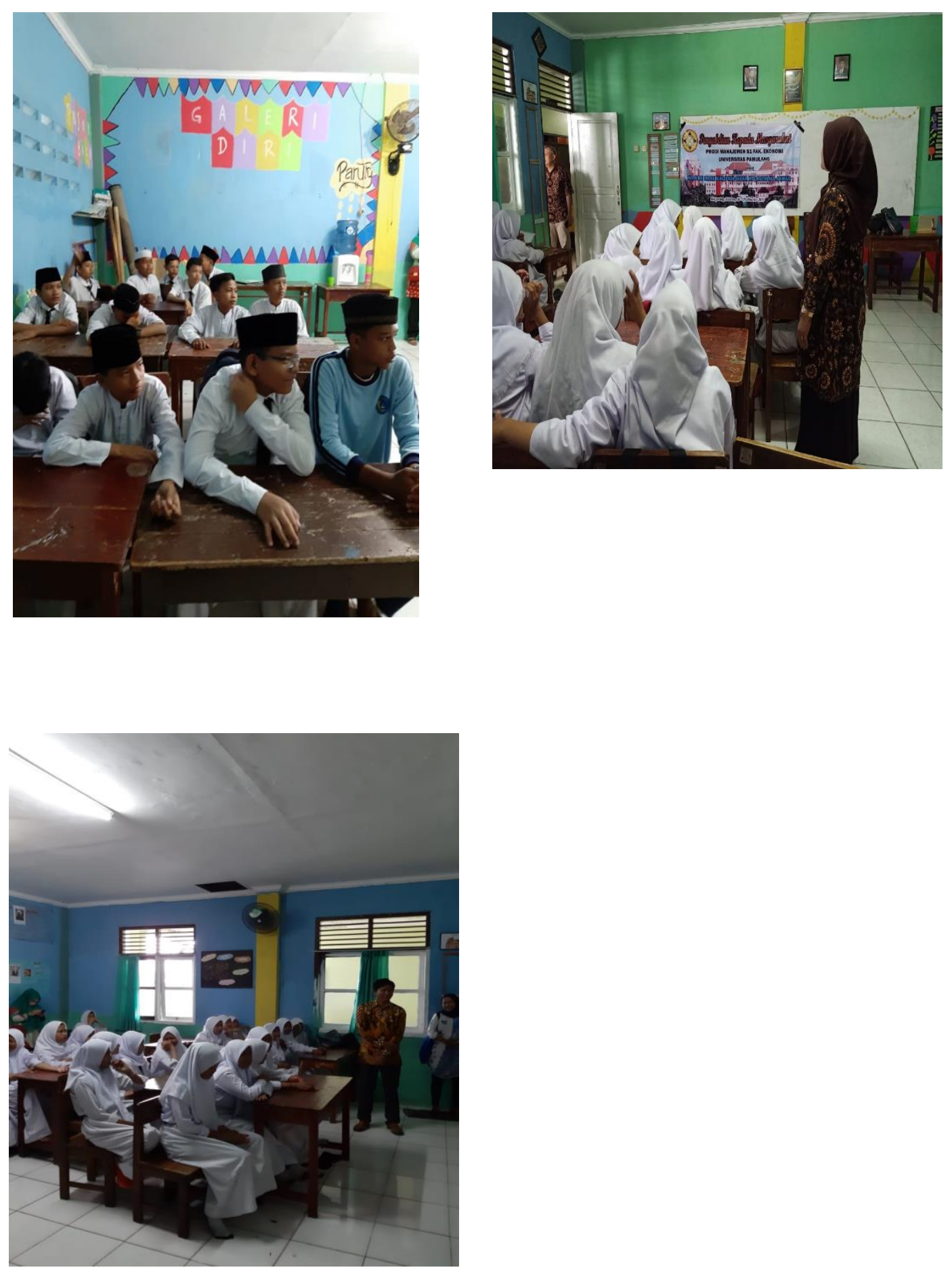